\title{
Estigmatización internacional y diplomacia cultural en América Latina*
}

\author{
International Stigmatization and Cultural \\ Diplomacy in Latin America
}

\author{
Sandra Montoya Ruiz**
}

\begin{abstract}
RESUMEN
Este artículo aborda tres posturas de manejo del estigma como aceptación, contra-estigmatización y rechazo del estigma, acogidas por Chile, Cuba y Colombia a inicios de la Posguerra Fría. El artículo se aproxima a las iniciativas de diplomacia cultural desplegadas en el contexto del estigma asociado a la violación de los derechos humanos en estos tres casos, y pone en evidencia el subexplorado status del estigma en la disciplina, así como sus desatendidas relaciones con la diplomacia cultural que emerge en sus contornos.
\end{abstract}

Palabras clave: Estigma - Diplomacia Cultural - Derechos Humanos - Política Exterior - Latinoamérica.

\footnotetext{
Este artículo surge del paper presentado en el X Congreso Latinoamericano de Ciencia Política (ALACIP), 31 de julio, 1- 3 de agosto de 2019. Instituto Tecnológico de Monterrey (México).

* Profesora de la Facultad de Estudios Internacionales, Políticos y Urbanos de la Universidad del Rosario, Colombia; Politóloga por la Pontificia Universidad Javeriana; especialista en Organizaciones Responsabilidad Social y Desarrollo por la Universidad de los Andes; Magíster en Asuntos Internacionales de la Universidad Externado de Colombia; Candidata a Doctora en Estudios Políticos e Internacionales por la Universidad del Rosario. Correo electrónico: $\underline{\text { sandra. }}$ montoyar@urosario.edu.co. ORCID: https://orcid.org/0000-0001-6011-418X. Recibido: $27 \mathrm{de}$ julio de 2020; Modificaciones: 7 de enero de 2021; Aceptado: 13 de enero de 2021.
} 


\section{ABSTRACT}

This paper addresses three stigma management positions, acceptance, counter-stigmatization and rejection of stigma, embraced by Chile, Cuba and Colombia in the early Post-Cold War. The paper approaches the cultural diplomacy initiatives deployed in the context of the stigma associated with the violation of human rights in these three cases, and highlights the under-explored status of stigma in the discipline, as well as its neglected relationships with diplomacy culture that emerges in its contours.

Keywords: Stigma - Cultural Diplomacy - Foreign Policy Human Rigths - Latin America. 


\section{INTRODUCCIÓN}

Desde el fin de la Guerra Fría, el mundo ha presenciado dos tendencias en ascenso que son subexploradas en Relaciones Internacionales $\mathrm{RI}^{1}$. La primera, se caracteriza por el uso de estigmas $^{2}$ para promover que los Estados cumplan normas y valores en el sistema internacional; en la segunda, el despliegue de diplomacia cultural por parte de Estados asociados al estigma, en el marco de su postura de contra-estigmatización, rechazo o aceptación del estigma. A la escasa literatura que aborda el estigma en RI, a la carencia de investigaciones sobre la diplomacia cultural desplegada en el marco del estigma, se suman la centralización de la literatura existente, producida y divulgada principalmente desde Alemania, Estados Unidos, Francia y Reino Unido. No obstante, desde inicios del siglo xxI crece gradualmente el interés sobre diplomacia cultural como objeto de estudio en y sobre el Sur Global en RI.

La estigmatización internacional es un proceso discursivo frente a "otro", $y$ opera a partir de la definición de desviación que se contrasta con una normalidad o un deber ser. Se trata de un proceso intersubjetivo que produce y

1 Utilizaré Relaciones Internacionales en mayúsculas para referirme a la disciplina, y su abreviatura RI.

2 Los estigmas son resultado de interacciones históricas que producen no solo comportamientos desviados, sino identidades desviadas, que pueden seguir "deterioradas" incluso después del cambio de comportamiento (Adler-Nissen, 2014). sostiene desigualdades y está anclado en historias y narrativas de prejuicio y exclusión (Alder, 2014). A lo largo de la historia, se encuentran casos de Estados, naciones y comunidades que han sido constituidos como infractores o desviados, acudiendo a etiquetas como "pícaros","parias","bárbaros", “incivilizados". Desde la segunda mitad del siglo xx a estas etiquetas y estigmas se suman las de "fallidos", "narcotraficantes/narco-estados", "violadores de derechos humanos", "terroristas".

Los procesos de estigmatización tienen implicaciones en el día a día de ciudadanos con nacionalidades estigmatizadas, entre ellas, la selectiva restricción a la movilidad internacional según la nacionalidad, en la que se generan dos tipos de ciudadanos, los que tienen pasaportes "poderosos" de pasaportes “débiles". Los primeros pueden moverse libremente por más del $81 \%$ de los 195 países reconocidos

3 De acuerdo a Passport Index, The Henley Passport Index, o The Nomad Passport Index 2017, los "pasaportes poderosos" permiten a sus ciudadanos ingresar a más de 160 países, como sucede con los pasaportes de Alemania, Dinamarca, Suecia, Finlandia, Luxemburgo, Italia, Francia, Noruega, Holanda, España, República de Corea, Estados Unidos, Bélgica, Austria, Suiza, Japón y Reino Unido. Los pasaportes débiles permiten a sus portadores el acceso a menos de 48 países, como sucede con los pasaportes de Afganistán, Iraq, Somalia, Siria, Sudán, Líbano, Eritrea, Etiopia, Yemen, Libia, Irán, Territorios Palestinos, Bangladesh y República Democrática de Corea. 
por las Naciones Unidas, mientras que los segundos solo pueden hacerlo en el $24 \%$ de los 195 países. Los pasaportes débiles provienen usualmente de Estados rotulados como "foco de amenazas a la paz, seguridad y estabilidad internacional".

Este artículo se aproxima al despliegue de diplomacia cultural de Chile, Cuba y Colombia, en el marco del estigma asociado a la violación de los derechos humanos a inicios de la Posguerra Fría. El documento se divide en tres partes, en la primera se aborda el status emergente del estigma en las RI, y el estigma asociado a la violación de los derechos humanos. En la segunda, se enfatiza la diplomacia cultural en relación al estigma, y algunas complejidades asociadas a la Guerra Fría en
Latinoamérica. En la tercera, se abordan elementos de los tres casos, entre ellos, la circulación del estigma, contextos y políticas exteriores en los que se enmarcan las iniciativas de diplomacia cultural desplegadas. Así, se recorrerán las posturas estatales aceptación del estigma adoptada por Chile en el proceso de transición a la democracia, contra-estigmatización adoptada por Cuba en el escenario post-soviético y bajo el bloqueo de Estados Unidos, y la postura rechazo del estigma adoptada por Colombia, durante el escalonamiento del conflicto armado interno, del narcotráfico y de la presión internacional en la lucha mundial contra las drogas. Al final se comparten algunos interrogantes que sigo indagando.

\section{EsTigma EN RI}

Aproximarse al campo del estigma en RI, y a la diplomacia cultural como posible respuesta a este en América Latina, contribuye a visibilizar la importancia de los roles de estigmatizador y estigmatizado, de normales y desviados en la construcción del orden internacional, y sus relaciones con la diplomacia cultural, por seis motivos: i) la construcción de la sociedad internacional ha tenido lugar a través de la estigmatización de Estados "transgresores" y que violan las normas, y sus formas de lidiar con el estigma (Adler-Nissen, 2014); ii) el uso de procesos de estigmatización no ha sido cuestionado en las corrientes dominantes de RI; iii) Este uso fomenta que la percepción de normalidad en el sistema internacional sea impartida por estándares de los estigmatizadores, usualmente occidentales ( $\mathrm{Za}$ rakol, 2014); iv) las imágenes de los países, las identidades estereotipadas y los símbolos culturales que son estigmatizados internacionalmente, pueden convertirse en preocupaciones de seguridad nacional para gobiernos y sus diplomacias (Villanueva, 2011); v) los procesos de estigmatización generan respuestas violentas y no violentas, siendo opacadas las no violentas 
como la diplomacia cultural; vi) analizar cómo se despliega la diplomacia cultural en el marco del estigma, amplía el entendimiento de las relaciones internacionales y las interacciones que su uso genera, permite visibilizar su carácter no violento ${ }^{4}$ (Donfried, 2015).

A pesar de sus implicaciones, hay poca literatura en RI, situación que contrasta con las robustas investigaciones sobre estigma que se ven en psicología social (Adler-Nissen, 2014), sociología, estudios de paz y estudios culturales. Mientras tanto, se observan diversos casos de Estados constituidos internacionalmente como infractores o desviados, "pícaros", "parias", "infractores de la ley", "bárbaros", "incivilizados", etiquetas a las que se suman de manera creciente desde el fin de la Guerra Fría, las de "fallidos", "narcotraficantes/narco-estados", "violadores de derechos humanos" y "terroristas". Casos, en los que además ocurren despliegues de diplomacia cultural enmarcados por el estigma, que siguen desatendidos en las RI.

4 Para Gandhi, la no violencia se identificaba con abimsa (no matar, no causar daño/sufrimiento) y con satyagraha (fuerza de la verdad y de la justicia). La no violencia se fundamenta en el respeto a la vida y a la dignidad de las personas, en la gestión de los conflictos sin utilizar ningún tipo de violencia. Los medios no violentos buscan modificar las lógicas existentes entre las partes en conflicto, cambiar las condiciones injustas que las sostienen y crear relaciones que posibiliten el entendimiento entre las partes. Ver Cohen (SF), Galtung (1990) y Martínez (2013).
Al revisar la literatura en RI, encontramos una interesante emergencia de análisis enfocados en la interacción entre actores que imponen un comportamiento "normal" -estigmatizadores- y los que son constituidos como transgresores, desviados, estigmatizados (Adler-Nissen, 2016). Tenemos también estudios que resaltan la necesidad de analizar el papel de los estigmatizados. Aunque el manejo del estigma como decisión estatal ha sido poco estudiado en RI, hay sugestivas aproximaciones desde la teoría social de la identidad y el interaccionismo social rescatado por la tercera generación de constructivistas (Adler-Nissen, 2016). En la teoría social de la identidad, el manejo del estigma se relaciona con la búsqueda de protección de autoestima colectiva; mientras que para constructivistas de tercera generación este manejo se relaciona con el que se le da a la vergüenza. Al recorrer la escasa y dispersa literatura que aborda estigmas internacionales, pueden identificarse los siguientes trece: i) atrasados-inferiores-retrasados; ii) tirano; iii) comunista; iv) financiador de terrorismo-terrorista; v) xenofóbico; vi) amenaza al orden democrático; vii) narcoestado-narcotraficante-productor de narcóticos; viii) violador de derechos humanos; ix) imperialista-belicista; x) robótico-desalmado-mecánico; xi) destino turismo sexual y prostitución infantil; xii) Estado canalla, y xiii) Estado fallido.

Los procesos de estigmatización internacional afectan a los 
estigmatizados más allá de una simple incomodidad por las críticas externas. Como enfatiza Goffman (1963), cualquier identidad, atributo o comportamiento puede ser estigmatizado a partir de atributos desacreditadores e incongruentes que sean distantes del estereotipo del tipo ideal de ser. Manejar el estigma y adoptar una de las tres posturas como decisión de Estado, representa un desafío que no solo involucra la lucha por lograr un mejor reconocimiento y status frente a otros, sino también relaciones con su propio pasado y conflictos domésticos, los cuales a su vez están moldeados por el mundo exterior (Adler-Nissen, 2016). Tomadores de decisión, en representación de los Estados, encarnan diversos desafíos en los contextos doméstico e internacional, en sus interconexiones, del manejo del estigma se desprenden dilemas éticos que se relacionan no solo con lograr un reconocimiento internacional adecuado, no estigmatizado, sino las relaciones de este proceso con problemáticas sociales, económicas, políticas y culturales que tienen lugar en sus sociedades.

A partir del modelo de Goffman, Adler-Nissen (2014) aborda tres posturas usadas por Estados para manejar el estigma. En la postura de aceptación o reconocimiento del estigma, se identifica y acepta la falta cometida que dio lugar al estigma, el Estado busca resarcir sus errores y se disculpa por su conducta/atributo transgresor, mostrando una resignificación de sí mismo. Alemania y Sudáfrica son dos ejemplos de esta postura, sus Estados reconocieron los errores del pasado, propiciaron la construcción de memoria histórica, resignificaron su imagen internacional alineada con el nuevo escenario. Otro ejemplo de aceptación es Chile a inicios de la Posguerra Fría, en medio de la efervescencia e incertidumbre trazada por el proceso de la transición a democrática post-dictadura. En la segunda postura, contra-estigmatización, los Estados convierten el estigma en un emblema de orgullo, deciden evidenciar la estigmatización como estrategia de los estigmatizadores, cuya legitimidad cuestionan; en esta postura se busca ser percibido como víctima y que el estigmatizador sea cuestionado internacionalmente, como sucede en el caso de Cuba. En la tercera postura, rechazo del estigma, los estigmatizados aceptan las categorías de desviación, pero niegan ser diferentes a los que viven en la norma; buscan pasar como normales y evitar ser sancionados, como sucede en el caso de Austria (Adler-Nissen, 2014), su Estado se autoreconoce como estigmatizado en la Unión Europea por las actitudes que tiene su extrema derecha, ofrece explicaciones de por qué no debería ser etiquetado como "transgresor", y centra su narrativa en ser discriminado. Otro ejemplo de esta postura de manejo del estigma es Colombia a inicios de la Posguerra Fría. 


\subsection{Estigma "Violador de Derechos Humanos"}

Al hablar de estigma en derechos humanos vienen a la mente múltiples situaciones de vulneración de los derechos humanos a los "estigmatizados",y que producto de este desconocimiento son impuestos los estigmas. Esta importante reflexión suele quedarse en el plano doméstico, y a enfocarse en el (in)cumplimiento del Estado en su responsabilidad de protección de los derechos humanos. Al llevar la discusión al plano internacional, se abren debates aplazados por la ideologización en torno a la importancia de los derechos humanos, a su tratamiento dialógico, intercultural, emancipatorio e incluyente a nivel internacional. Como lo señala Marín (2018), la actual "hegemonización" en la búsqueda de los derechos humanos resulta problemática para el carácter movilizador y emancipatorio de estos derechos, ese carácter que ha acompañado diversas luchas sociales y de resistencias en contra de variadas formas de opresión alrededor del mundo. Para este autor, desde la segunda mitad del siglo xx y lo que va del xxi, los derechos humanos y su discurso dominante - con su origen geocultural occidental- se han constituido en un referente normativo y valorativo a nivel global, un parámetro de normalidad en el orden internacional bajo el cual organismos internacionales, sistemas de protección de los derechos humanos, Estados, vienen adoptando principios asociados a su defensa a nivel doméstico y hacia otros países.

Hablar de estigmatización en el ámbito de los derechos humanos es desafiante, dado el carácter de orden esencialmente normativo de los derechos humanos mismos, su legitimidad relacionada con la adhesión de una enorme mayoría de Estados miembros de Naciones Unidas a instrumentos universales de derechos humanos ${ }^{5}$, y el respaldo militante de organizaciones de la sociedad civil global actuante en el sistema multilateral. Hablar de estigma en derechos humanos, permite reconocer el uso de la propaganda - y la contra propaganda - en materia de derechos humanos como herramientas de políticas, que han sido usadas bajo diversos motivos y causas, entre ellas con fines de impactar la opinión pública interna y externa; sin obviar la importancia de los contextos particulares, las voces de las poblaciones, sus historias, sus lecturas del presente, pasado y futuro.

En los últimos cuarenta años, un importante número de Estados han sido vinculados al estigma asociado a la violación de derechos humanos, en indicadores internacionales, en listados emitidos por Estados, agencias y/u organizaciones multilaterales

5 Dentro de estos instrumentos se resaltan los Pactos de los Derechos Civiles y Políticos, de los Derechos Económicos, Sociales y Culturales y las Convenciones contra la Tortura, contra las Desapariciones Forzadas, y el reconocimiento de la Declaración Universal de los Derechos Humanos de 1948. 
que difunden la situación de los Estados en materia de derechos humanos. Desde finales de esa década y hasta 2001, veintidós países (Lebovic y Voete, 2006; Tolley 1984) ${ }^{6}$ fueron condenados cada año a través de resoluciones de la entonces Comisión de Derechos Humanos de las Naciones Unidas (CDH), y/o fueron objeto del mayor número de sus recomendaciones. Decidir manejar el estigma, y asumir una postura estatal para ello, fue particularmente complejo en un contexto internacional en el que se posicionan la protección de los derechos humanos, la búsqueda de la democracia, las expresiones de diversidad, las tensiones de las identidades locales como temas clave en la agenda internacional, un contexto que ambienta el despliegue de diversas iniciativas de diplomacia cultural en el que convergen múltiples actores.

\section{Diplomacia cultural en medio del estigma}

${ }^{6} \mathrm{La}$ diplomacia cultural es el conjunto de acciones que están basadas en y/o utilizan el intercambio de ideas, valores, tradiciones y otros aspectos de la cultura o identidad para fortalecer las relaciones, facilitar cooperación socio-cultural o promover los intereses nacionales, en reconocimiento del contexto histórico, bajo una agenda, por parte de diversos agentes, a través de vehículos, y en una audiencia destino (Gienow-Hecht \& Donfried, 2010; Donfried, 2015, Montoya, 2017).Esta diplomacia busca contrarrestar etiquetas negativas, estereotipos, discriminación, y propiciar el conocimiento por parte de diversas audiencias y escenarios

6 Estos países son: Afganistán, Bolivia, Burma, Burundi, Camboya, Colombia, Cuba, Chile, Chipre, Guatemala, El Salvador, Grecia, Guinea Ecuatorial, Guyana, Haití, Iraq, Irán, Irlanda del Norte, Israel, Marruecos, República Democrática del Congo, Sudáfrica y Sudán. internacionales, de las narrativas de actores encarnados que son asociados al estigma o invisibilizados por este, desde sus voces e identidades y expresiones de su cultura, y así ampliar los márgenes de los referentes que circulan sobre lo que son sus historias y su presente. A través de la diplomacia cultural se despliegan narrativas para situar significados específicos y contrarrestar, corregir o ampliar lo que los Estados y otros actores, perciben es un "reconocimiento distorsionado o incompleto". La diplomacia cultural es uno de los caminos para desplegar soft power?

$\mathrm{Al}$ revisar la minúscula literatura en RI que aborda el uso de la diplomacia

$7 \quad$ Según Nye (2004), el soft power es la habilidad de obtener lo que se desea a través de la atracción, crece a partir de la atractividad que generan la cultura, ideales políticos y políticas exteriores de los países, y se basa en la persuasión. 
cultural en el marco de un estigma, se encuentran estudios de caso y análisis comparado, mayoritariamente sobre países occidentales y durante el siglo xx, en particular Estados Unidos, Reino Unido, Francia y Alemania, en donde además se ubican los centros de pensamiento que más estudios en diplomacia cultural han realizado y difundido. Dentro de la emergente literatura sobre países estigmatizados y el uso de la diplomacia cultural en la que no siempre son atendidas las relaciones estigma-diplomacia cultural一, se pueden identificar cinco categorías dispersas entre sí: i) países vencidos en la II Guerra Mundial; ii) países enfrentados en y/o por la Guerra Fría; iii) tesignificación del pasado de conflicto armado; iv) manejo de estereotipos del islam.

En la primera categoría, prevalecen investigaciones sobre el emblemático caso de Alemania, (Rossbach, Hayes, Wilson, Kleinheider, Myers, Westfall, \& Haakenson, 2013; Adler-Nissen 2014, 2017; Alexander, 2016; Wood, 2017), su diplomacia cultural en el manejo del estigma "amenaza nazi" y resignificación internacional. En la segunda categoría, se ven estudios de la diplomacia cultural estadounidense y soviética, usadas para contrarrestar la estigmatización de la contraparte en la Guerra Fría (Zourek, 2017). En la tercera categoría se observan análisis de la desestigmatización mutua, por ejemplo, del caso de las Coreas del Norte y Sur, en el marco de la política surcoreana Sunshine (Son, 2007). En la cuarta categoría se encuentran estudios sobre países musulmanes que deben sortear una imagen regional que les cataloga como "mundo árabe autocrático, retrógrado-conservador y antipático, campo de guerra contra el terrorismo y competencia de Occidente" (Cooper y Momani, 2009); entre ellos, análisis del caso de Irán y su soft power desplegado vía diplomacia cultural para enfrentar su demonización liderada por Occidente (Wastnidge, 2015). A estos casos se suman estudios que enfatizan la cobertura mediática global a la violencia, narcotráfico y criminalidad en México y el posible uso de la diplomacia cultural en defensa de la imagen mexicana (Villanueva, 2011); así como de la diplomacia cultural presente en el período de Confucio (551 AC-479 AC) y su uso en la China contemporánea para contrarrestar el estigma de "fuerza desestabilizadora del orden internacional” (Sinah, 2013).

\subsection{Guerra Fría cultural, derechos humanos y estigma en América Latina}

El despliegue de la diplomacia cultural en el marco del manejo del estigma tuvo lugar en Latinoamérica, a inicios de la Posguerra Fría, suele pasar inadvertido en la literatura de RI. Atender las experiencias de diplomacia cultural en este período permite visibilizar procesos de agencia desplegada por diversos actores, en torno a su cultura, especialmente aquellos librados en América Latina durante el complejo 
contexto de finales de la Guerra Fría, sus connotaciones particulares, desde una perspectiva cultural y desde los agentes de diplomacia cultural.

Calandra y Franco (2012) sostiene que al contexto latinoamericano es posible aplicar la categoría de Guerra Fría Cultural propuesta por Saunders (1999, 2001), pues en ella se refiere a "una densa red de actores, prácticas y estrategias comunicativas que en la esfera de la diplomacia cultural [...] y en el marco cronológico de la Guerra Fría contribuyeron de manera esencial a la exportación del American Way of Life en el subcontinente, incluyendo las múltiples formas de su recepción y reelaboración a nivel local" (Calandra y Franco, 2012:11). La "batalla por la conquista de las mentes humanas y sus corazones" entre Estados Unidos y URSS se libró en América Latina vía periódicos, libros, conferencias, seminarios, exposiciones, conciertos, premios, dibujos animados, películas, series de televisión - entre otros-, para llevar a cabo grandes campañas de persuasión. Las potencias enfrentadas desplegaron su poder con "representaciones, sistemas simbólicos y nuevas tecnologías, a través de las redes de negocios y comunicaciones de las industrias culturales" (Joseph, 2004: 80), ambientadas en el hemisferio occidental, por numerosas acciones del poderío político y militar estadounidense. ${ }^{8}$ La Guerra Fría en Latinoamérica, además de un asunto de políticas e intervenciones gubernamentales y de los actores de las élites, fue también resultado del "entrelazamiento a través del lenguaje y de los sistemas simbólicos, con las prácticas sociales cotidianas" (Calandra y Franco, 2012:28).

En este contexto fueron edificados los sistemas de protección de los derechos humanos en las Naciones Unidas, y en la Organización de Estados Americanos (OEA). Durante las primeras cuatro décadas del Sistema Interamericano de Derechos Humanos (SIDH), en la región fueron reemplazados trece gobiernos constitucionales por dictaduras militares respaldadas por Estados Unidos, se celebraron conferencias de la oeA en las que se impulsó la solidaridad de los Estados del hemisferio contra "la intervención del comunismo internacional”-entre ellas la de Caracas, en 1954- Los Estados latinoamericanos, como los de otras

8 Entre estas acciones se encuentran: los apoyos a los derrocamientos de Prío Socarrás en Cuba (1952) y del gobierno de Árbenz elegido democráticamente en Guatemala (1954); el apoyo al intento de golpe de Estado a Joao Goulart en Brasil (1964); los envíos de militares a República Dominicana (1965), y de armas, asesores y militares a Guatemala para la campaña contrainsurgente (1966); los múltiples intentos de la CIA para asesinar a Fidel Castro corroborados en The Washington Post (1971); el apoyo a la toma y mantenimiento de dictaduras militares en el cono sur (Uruguay y Chile 1973, Argentina 1976) y la invasión a Granada (1983). Ver Engstrom, 2015. 
regiones, jugaron un importante papel en la creación del régimen internacional de derechos humanos, (Schulz y Levic, 2019) ${ }^{9}$ y, al mismo tiempo, algunos Estados respondieron al estigma en el marco del sidH, que no siempre fue escenario de acatamiento a las acusaciones de "violadores de derechos humanos", sino un escenario para su contestación, como sucedió con Panamá en 1977 y Nicaragua en $1981^{10}$

Con el inicio de la Posguerra Fría, en una región con tendencia mayoritariamente democrática, diversos Estados no solo reconocen los efectos del estigma asociado a la violación de derechos humanos, el deterioro de su imagen internacional, sino que además lo manejan. En este manejo, se atravesaban relaciones particulares con los procesos internos en sus sociedades y su pasado. En este marco tiene lugar el despliegue de iniciativas de diplomacia cultural, dentro de las cuales las experiencias de Chile, Colombia y

$9 \mathrm{Al}$ analizar, Schulz y Levic evidencian que el compromiso de los Estados latinoamericanos con los tratados multilaterales adoptados entre 1945 y 2018, que están depositados en la base de datos del Secretario General de la onu (MTDSG), es similar al que muestran los Estados en otras regiones, a excepción de Europa.

10 En el caso de Panamá, el Presidente Torrijos usó el siDH para responder a las acusaciones de violaciones a los derechos humanos hechas por parte de sus oponentes en el Senado estadounidense. En el caso de Nicaragua, el gobierno sandinista acudió al SIDH para responder a las acusaciones de Estados Unidos de violaciones a los derechos humanos. Ver Engstrom, 2015.
Cuba son ventanas privilegiadas para aproximarse al sorprendente despliegue que pone la cultura, la creatividad y la identidad en el centro de las interacciones internacionales y locales, como plataforma de (re)encuentro.

\subsection{Chile: diplomacia cultural y aceptación del estigma}

La alarmante situación de derechos humanos ocurrida durante el período de Pinochet fue conocida por sistemas internacionales de protección de derechos humanos, abordada en quince Asambleas Generales de las Naciones Unidas —entre 1973 y 1988—, por la Comisión de Derechos Humanos de las Naciones Unidas (CDH) en 1973 y 1975 (Wilhelmy y Durán, 2003:276), y por la Comisión Interamericana de Derechos Humanos (CIDH) en sus informes de 1974, 1977, 1976 y 1985, a las cuales se sumaron testimonios y denuncias de chilenos exiliados en el exterior. El valiente activismo de los exiliados tuvo resonancia en políticos y activistas en Europa y Estados Unidos, logrando visibilizar la violación de la vida y dignidad de aquellos que eran considerados enemigos o críticos del régimen militar, dejando "en un país de solo diez millones de personas en 1973, [...] casos probados de muerte o desaparición por agentes del Estado (o por personas bajo su mando) [que] ascienden a unos 3.000; víctimas de tortura llegan a decenas de miles; arrestos políticos documentados exceden los 82.000, y el flujo de 
exiliados alcanza unos 200.000" (Stern, 2010:24).

A inicios de la Posguerra Fría, el Estado chileno contaba con una imagen internacional contradictoria, de un lado, manchada por la violación de derechos humanos ocurrida bajo el gobierno de Pinochet, políticamente reprochado por democracias occidentales y regímenes de "socialismo real" (Wilhelmy y Durán, 2003); del otro, un destacado y creciente desarrollo económico. Ante esta imagen ambigua, $\mathrm{y}$ ante el cambio de circunstancias a partir de 1990 en Chile, se propició una postura estatal de aceptación de errores del pasado, ante la que ya no operaban las resoluciones críticas sobre la situación de derechos humanos, y en la que el proceso de transición a la democracia se convertía en el foco.En esta postura de aceptación, según Goffman (1963) y Adler-Nissen (2014), se da lugar a una identificación de la necesidad de corregir un pasado, asociado a la violación de derechos humanos; el Estado internaliza el juicio de valor que le cataloga como violador de derechos humanos por lo sucedido bajo Pinochet, intentando maniobrar un delicado proceso en el que debe trasmitir compromiso institucional con la democratización, insertarse internacionalmente con una imagen desmarcada de ese pasado reciente, todo esto sin poner en riesgo la transición misma.

En el período de análisis en el que nos situamos, la administración de Eduardo Frei Ruiz-Tagle (1994-2000), segundo período de la Concertación, el proceso político chileno interno adquiere visibilidad internacional, apoyada por gobiernos, partidos políticos, ongs, académicos, ${ }^{11}$ medios de comunicación internacional y exiliados (Wilhelmy y Durán, 2003; Avaria, 2015). Bajo un enfoque multilateral de política exterior para la transición, Chile diversifica sus relaciones internacionales, proceso que inicia el gobierno de Aylwin (1990-1994). El Presidente Patricio Aylwin buscó generar credibilidad internacional al regreso de la democracia en Chile, y aumentó su participación en escenarios globales, regionales y bilaterales. Chile logró respaldo de la comunidad internacional, empezando con la presencia de doce presidentes y del vicepresidente de los Estados Unidos en la inauguración presidencial de Aylwin; numerosos Estados americanos y europeos, con los que fueron restablecidas las relaciones congeladas bajo el período de Pinochet, expresaron su apoyo.

La oEA fue uno de los escenarios privilegiados para propiciar el desmarque internacional del presente chileno con su pasado reciente. Como sede de la xxi Asamblea General oEA en 1992, el Estado chileno trasmitió su postura de aceptación y compromiso con

11 Entre los académicos y luego funcionarios públicos que participaron en el diseño de la política exterior para el restablecimiento de la democracia se encuentran: José M. Insulza, Heraldo Muñoz, Juan Somavía, Juan G. Valdés, Carlos Portales y Alberto van Klaveren. Ver Wilhelmy y Durán, 2003. 
la democracia, dio lugar al "Compromiso de Santiago con la Democracia y la Renovación del Sistema Interamericano" y a la firma de la Resolución 1080 (Emergson, 2003). Este mismo año Chile es elegido como miembro de la Comisión de Derechos Humanos de Naciones Unidas, y un año antes, fue elegido miembro del Consejo Económico y Social de la onu (1991).

La promoción de la democracia adquiere protagonismo en la política exterior chilena, una labor que se conjuga con el inicio de la participación del país en operaciones de paz bajo el mandato de las Naciones Unidas (Van Klaveren, 2012; Milet,2012). Chile celebra acuerdos de libre comercio y de complementación económica con Argentina, Bolivia, Canadá, Colombia, México y Venezuela, e implementa una política de profundización de sus relaciones con países del Sudeste Asiático, inicia el proceso para ingresar al Foro de Cooperación Económica Asia Pacífico (APEC). Bajo el período de Aylwin también se desplegaron iniciativas de diplomacia cultural para afirmar la imagen de Chile y contribuir a la reconstrucción de vínculos interrumpidos durante el período $\mathrm{Pi}$ nochet. Por ejemplo, en la Embajada de Chile en Hungría, a inicios de los ' 90 , se organizaron diversas presentaciones del Ballet del Teatro Municipal de Santiago en la Opera de Budapest, a las cuales asistieron el Presidente húngaro Arpad Göncz, así como los directores de orquesta chilenos Juan
Pablo Izquierdo y Francisco Rettig, dirigiendo los conjuntos húngaros (1992 y 1993).

El gobierno de Frei Ruiz-Tagle continúa la reinserción de Chile en el mundo. En Indonesia, en su primera participación en la Cumbre de Líderes de apec en 1994, Chile se compromete a lograr las metas acordadas para el libre comercio entre las economías APEC para el año 2010, transmitiendo una actitud diferente a la esperada para economías en desarrollo que tenían como plazo 2020. Chile vuelve a ser miembro no permanente del Consejo de Seguridad de las Naciones Unidas en el bienio 1996-1997, luego de 30 años de dejar esta posición, y transmite compromiso con la paz y protección de los derechos humanos en casa y en el mundo (Wilhelmy y Durán, 2003). El Estado se pronuncia ante los conflictos y crisis humanitarias de Etiopía, Burundi, Iraq, la Península de los Balcanes, defiende las minorías kurdas, la población iraquí y las víctimas de Bosnia-Herzegovina (Milet, 2012).

En este proceso, el Estado acompaña diversas iniciativas de diplomacia cultural. Se amplía la labor de ProChile más allá de la difusión del modelo económico chileno y la diplomacia comercial que ya ejercía en el período Pinochet, desde su creación (Van Klaveren, 2011). Una de las apuestas internacionales fue la campaña de imagen internacional diseñada para la participación chilena en Expo Sevilla 1992, en la que se usa un iceberg de la Antártica para transmitir una imagen de nación 
fría, seria y formal, con democracia recuperada, éxito económico y sus recursos naturales (Jiménez, 2013).ProChile realiza una investigación para conocer la imagen que sobre el país tienen ciudadanos extranjeros, encontrando que en Europa se tenía una imagen difusa o negativa asociada a la violación de derechos humanos, y que en Estados Unidos se le asociaba con México, uvas y vino (Ministerio de Relaciones Exteriores de Chile,1992). En 1993 ProChile lanza una campaña de imagen en Estados Unidos, principal socio comercial en ese momento, para posicionar el turismo, gastronomía, software, salmón, vino y frutas (Prieto, 2011).

Bajo el período de Frei Ruiz-Tagle, el presupuesto de la promoción internacional de Chile aumenta, así como el número de países en los que se desplegaría el soft power chileno, incrementando con ello el número de semanas culturales chilenas organizadas por las embajadas (Cárcamo y Riveros, 1998). El arte y la cultura fueron plataformas de reencuentro entre diversos actores. La música y el cine ocuparon un rol central, con ciclos de cine chileno propiciados por misiones diplomáticas en el exterior, a lo cual se sumó el reconocimiento internacional de películas chilenas como "Coronación”, "El Charcotero Sentimental,"
"Gringuito" e "Historias de Fútbol”. En música se realizaron conciertos internacionales acompañados y/o difundidos por el Estado, presentaciones de Bafochi, Ensamble Bartok, Felipe Browne, Los Jaivas, Inti Illimani, la Orquesta de Cámara de Chile dirigida por el maestro Fernando Rosas, Quilapayún, entre otros. En Teatro, se realizaron exposiciones de obras de arte plásticas, fotografía, también en la escena internacional.

Ahora bien, la circulación internacional del estigma asociado a la violación de derechos humanos apaciguado a finales de los ' 90 , recircula internacionalmente con la detención de Pinochet en Londres, en 1998. El activismo de los exiliados que despertó y mantuvo vivo el interés internacional sobre la dictadura y en la transición, se hizo también presente a través de sus vínculos trasnacionales, ante las $\mathrm{Na}$ ciones Unidas, el Congreso de Estados Unidos y el Parlamento Europeo, que apoyó internacionalmente el plebiscito de 1988 con el cual Chile dejaba atrás la dictadura (Avaría, 2012).

El gobierno chileno defendió la necesidad de que Pinochet fuese juzgado en el país por los "presuntos" delitos que motivaban la solicitud de su extradición por parte del Juez español Baltazar Garzón. Una postura que, desde 
la detención de Pinochet en Londres ${ }^{12}$ y hasta su regreso a Chile, representó un golpe complejo para la imagen internacional del Chile post-dictadura y para las víctimas. Emergían percepciones de una brecha entre la postura estatal y la imagen de un Estado en transición distanciado de Pinochet, al que se asociaba directamente con la violación de los derechos humanos. El proceso que ello derivó, en Chile y en el exterior, reactivó la demanda por la verdad, justicia, por la memoria (Stern, 2010), que se veía tensada por la interpretación de riesgosas implicaciones que traería un enjuiciamiento internacional de Pinochet, no solo para la justicia chilena, sino para las elecciones presidenciales en las que se jugaría la continuidad de la transición misma.

En este escenario, la cultura no se detuvo; no se apagó. Al cierre de la administración de Frei Ruiz-Tagle, se celebró la Expo-Cumbre de las Américas que acompañó a la Cumbre de Presidentes del continente en abril de 1998, en Santiago, con una muestra cultural de los países participantes realizada en

12 Pinochet fue detenido en 1998 en la London Clinic. El juez español Baltazar Garzón pidió su extradición a España luego de que la justicia española aceptara la denuncia presentada por la Unión Progresista de Fiscales (UPF) de España contra Augusto Pinochet y los dirigentes de la Dirección de Inteligencia Nacional (DINA). Pinochet fue repatriado a Chile en el año 2000. El proceso surtido sentó un precedente para la actuación de jueces nacionales ante casos de individuos de terceros países asociados a la violación de los derechos humanos (Ver Montes, 2018). el Centro Cultural Estación Mapocho. A fines de 1999, con una destacada participación chilena, como país invitado de honor en la Feria Internacional del libro de Guadalajara, se resaltó la presencia de reconocidos escritores, músicos, artistas plásticos y del teatro ${ }^{13}$ chilenos (Navarro, 2019).

\subsection{Cuba: diplomacia cultural y contra-estigmatización}

Las narrativas sobre la situación de los derechos humanos en Cuba circulan en foros internacionales desde los años ' 60 , especialmente en la OEA y en la onu. La oea ha sido un interesante escenario para el despliegue de la estrategia estadounidense dirigida a aislar al gobierno de Fidel Castro en el hemisferio (Heller, 2003: 626). Esta estrategia, que inicialmente "no se basó en la supuesta represión del régimen, o en la violación de los derechos humanos por parte del mismo" (Shoultz, 2014:16,17), con el paso del tiempo conjugó la promoción del fortalecimiento de la democracia contra

13 Entre los participantes chilenos, se encontraban en esta Feria Internacional del Libro los escritores Gonzalo Rojas, Volodia Teitelboim, Poli Délano, Antonio Skármeta, Raúl Zurita, Ana María del Río, Alberto Fuguet, Marcela Serrano; los grupos de música "Los Jaivas","Los Tres," “IIIapu”,"Inti Illimani",y las compañías de Teatro de Julio Jung y la Troppa. En este certamen fueron proyectadas las películas "Historias de Fútbol"; "Gringuito" " "Julio comienza en Julio" (Navarro, 2019). 
el comunismo y el seguimiento a la situación de derechos humanos.

La expulsión de Cuba de la oEA, en 1962, no mantuvo a la isla ajena al radar del sistema interamericano. Entre 1962 у 2000, la CIDH emite siete informes sobre el país (1962,1963,1967,1970,1976, 1979 y 1985), en los que la situación de derechos humanos de la isla prende las alarmas del sistema interamericano. Cuba también figura en la agenda de la Comisión de Derechos Humanos de la ONU - CDH—-(Heller, 2003). La presión estadounidense en la $\mathrm{CDH}$ fue inicialmente contenida por el Grupo de Contadora ${ }^{14}$ que facilitó no solo que voluntariamente el gobierno cubano invitara a una misión de la CDH a visitar al país, sino la expedición de la resolución 1989/113 en la que Cuba se comprometía a cooperar con el Secretario General de la onu para abordar los resultados del informe de la misión. Con el fin de la Guerra Fría, ante un debilitado bloque soviético-socialista, las presiones ejercidas por Estados Unidos en la CDH alcanzaron el respaldo necesario para expedir la resolución 1991/68, con la cual se designó un Relator Especial de la CDH encargado de preparar un informe sobre Cuba. A partir del informe, la situación de derechos humanos en Cuba es motivo de resoluciones de la Asamblea General de las Naciones Unidas en 1993, 1994

14 El Grupo Contadora fue una instancia multilateral establecida por los gobiernos de Colombia, México, Panamá y Venezuela a inicios de los 1980, para promover conjuntamente la paz en Centroamérica. y 1997, a las cuales se sumaron las emitidas por la CDH en 1995 y 1996 (Heller, 2003), que inciden en la activación internacional del estigma asociado a la violación de los derechos humanos para el caso de Cuba.

En esta activación del estigma, también incidió el activismo de diversas oNGs defensoras de derechos humanos y de exiliados cubanos. En 1991, por ejemplo, Amnistía Internacional expidió tres comunicados apoyados por ongs locales y por otras fuentes en la isla, y realizó consecutivos informes anuales (1991-1996) ${ }^{15}$ que precedieron las sesiones de la $\mathrm{CDH}$, en los que se visibilizan casos puntuales de presuntas violaciones de los derechos en la isla. También, la resonancia del activismo de cubanos exiliados en Estados Unidos, particularmente en políticos y otros activistas fue contundente. Durante el período de Reagan, la ONG Cuban American National Foundation $(\mathrm{CANF})^{16}$ recibió recursos de la agencia federal National Endowment for Democracy (NED), a lo cual se

15 Amnistía Internacional alertó sobre los presos de conciencia en detención, los presos políticos condenados o en espera de juicio por acusaciones como sabotaje, terrorismo y espionaje; así como pidió la despolitización de la CDH para abordar la situación en Cuba (ver Amnistía Internacional, 1991, 1992, 1993, 1994, 1995, 1996).

16 Según Torres (1999), a pocos meses de las elecciones presidenciales estadounidense de 1980, un grupo de empresarios e ideólogos cubanoamericanos formó la CANF. En 1988 la CANF recibió 390.000 dólares de la NED, destinados a difundir información sobre los derechos humanos en Cuba. 
sumaron los puestos gubernamentales ocupados por exiliados cubanos en Estados Unidos ${ }^{17}$ (Torres, 1999). La campaña presidencial de George $\mathrm{H}$. Bush resalta el interés del país sobre la situación de los derechos humanos en Cuba, y como Presidente nombra a Valladares ${ }^{18}$ embajador de Estados Unidos ante la $\mathrm{CDH}$, medida que fue acompañada por el incremento del bloqueo económico propiciado por la Ley Torriceli o Cuban Democracy $A c t^{19}$ de 1992 (Suárez 1994, Torres, 1999).

A este complejo contexto de inicios de la Posguerra Fría, se suman la coyuntura del llamado período críti$\mathrm{Co}^{20}$ o período especial en Cuba $(1990$ 1996), caracterizado por caídas en un $35 \%$ del PIB, $75 \%$ de las importaciones y $80 \%$ de sus de exportaciones. En este

17 A mediados de los '80, los alcaldes de Miami, Hialleah, West Miami, y de otros municipios estadounidenses, eran cubanos; así como diez cubanos-estadounidenses se desempeñaban en la legislatura norteamericana. Ver Portes, 2003.

18 Armando Valladeres fue preso político en Cuba durante 22 años, y liberado en 1982. Ver Torres, 1999.

19 Esta ley establece que las embarcaciones que comercialicen con Cuba no pueden arribar a puertos estadounidenses en seis meses; si son empresas estadounidenses radicadas en terceros países deben pagar un monto similar a los intercambios que tengan con Cuba; los países que mantengan relaciones con Cuba pueden ser excluidos de beneficios otorgados por Estados Unidos. Ver Suárez, 1994.

20 Este fue llamado "período especial" por Fidel Castro durante el XII Período de Sesiones Ordinarias de la Asamblea Nacional del Poder Popular, el 31 de octubre de 1992. Ver Suárez 1994. período escasean alimentos, combustibles, manufacturas e insumos en el país; se desploman los precios de sus principales productos de exportación (azúcar, níquel, cítricos); se consolida la deuda externa en US\$ 6.500 millones a 1991, e impera la incertidumbre por la reciente desintegración de la URSS (Ruiz, 2015). En este desafiante marco, la política exterior cubana se resignifica, ${ }^{21}$ y en ella la diplomacia cultural reafirma la postura estatal de contra-estigmatización frente a los derechos humanos.

Desde su postura de contra-estigmatización, el estigma por la violación de derechos humanos es tratado por Cuba como parte de una estrategia internacional liderada por Estados Unidos para propiciar su aislamiento y el derrumbe de su sistema socialista. Esta estrategia es percibida por Cuba como una evidencia adicional de discriminación e injusticia, y un motivo adicional a la postura anti-sistémica cubana, que - como afirma Adler-Nissen (2014) - es característica de esta postura de manejo del estigma. Bajo

21 Entre los énfasis de la política exterior cubana se encuentran: 1 . Defender la soberanía nacional y las principales conquistas del socialismo; 2. Derrotar o modificar el bloqueo económico y político que fortalece a Estados Unidos; 3. Adoptar un enfoque multilateral en organismos intencionales, para defender intereses de países del Tercer Mundo; 4. Desarrollar relaciones económicas, políticas, culturales y científico-técnicas; 5. Realizar acciones de solidaridad con Cuba y con otras sociedades (Suárez, 1994). 
ella, Cuba busca deslegitimar a Estados Unidos; poner en duda su autoridad moral, y visibilizarlo como victimario, mientras se manifiesta contra el poder estadounidense para - como lo expresa Capote- "imponer su dominio a escala globaly proliferar conceptos tales como delimitación de la soberanía, introducción de la selectividad en materia de derechos humanos, ${ }^{22}$ y la [...]injerencia en los asuntos internos" (2009: 67).

En este mismo período emerge en la onu el repudio internacional contra el gobierno estadounidense y claro respaldo a Cuba, a pesar de las denuncias sobre violación de derechos humanos. Durante el último trienio, Estados miembros de la onu se pronuncian en contra del bloqueo estadounidense hacia Cuba en sus votaciones de las resoluciones sobre el tema. El apoyo a Cuba se incrementa entre 1992 y 1996, pasando de 59 votos a favor a 117; de 71 abstenciones a 25 , manteniéndose los mismos 3 votos, entre ellos, el de Estados Unidos (MINREX, 2018: 41). Este respaldo internacional se atribuye a la política exterior cubana (Romero, 2017).

Bajo esta coyuntura, el despliegue de diplomacia cultural cubana es ambientada a través de iniciativas que buscan una imagen internacional

22 Entre 1991-2001, la CDH aprobó resoluciones denunciando abusos cometidos por 24 países, de los cuales los más frecuentemente condenados son: Israel, Irak, Irán, Afganistán, Marruecos, Guinea Ecuatorial, Birmania, Cuba, la República Democrática del Congo, Sudán y Burundi. (Lebovic y Voeten, 2006). positiva, en sintonía con la promoción de valores humanistas y críticas a la influencia de Estados Unidos en la estructura vigente del sistema internacional. Entre estas iniciativas se encuentran las visitas de solidaridad, y el incremento de relaciones e intercambios técnicos y culturales con países como Angola, Argelia, Botsuana, Burkina Faso, Egipto, Indonesia, Irán, Guinea Bissau, Gana, Namibia, Nigeria, Siria y Zimbabue (Suárez, 1994). Adicionalmente, se continuó con la ejecución de los programas Becarios Extranjeros y Alfabetización "Yo, sí puedo”, se creó el Instituto Pedagógico e Iberoamericano (IPLAC) y surgió la Escuela Latinoamericana de Medicina (Ruiz, 2015). El programa "Yo, sí puedo" posiciona a Cuba como referente internacional de alfabetización ${ }^{23}$. La colaboración internacional en salud se nutre de los intercambios educativos favorecidos por el programa de becas completas dirigidas a estudiantes de medicina y profesionales de la salud. Los intercambios científicos en Medicina suman frentes de acción de la diplomacia cultural cubana, con la que se moviliza internacionalmente el prestigio del modelo pedagógico cubano en Medicina, incrementado posteriormente con la creación de la

23 Este programa tiene dos Menciones Honoríficas del Premio "Rey Sejong” (2002 y 2003), y es ganador de este premio en 2016. 
Escuela Latinoamericana de Medicina, ELAM $^{24}$.

En cuanto a iniciativas de diplomacia cultural en cine, la visibilidad internacional del séptimo arte se despliega con películas taquilleras como "Fresa y Chocolate"25 (1993), primera cinta cubana en recibir premio a Mejor Película Extranjera en los Premios Oscar (1994), que tiene la homosexualidad como centro. La actividad de cineastas cubanos continúa, entre ellos con importantes reconocimientos internacionales de películas como "Adorables Mentiras","Madagascar,"Hello Hemingway,"“Guantanamera,"'Pon tu pensamiento en mí" y el "El Fanguito". El apoyo al arte como forma de vida,se manifiesta además a través de las labores de la Escuela Internacional de Cine y TV, la celebración del emblemático Festival de Nuevo Cine Latinoamericano de La Habana y los conciertos de artistas cubanos como los de la Orquesta Aragón, Omara Portuondo, la Big-Band de Cuba, Orquesta la Revé, Edesio Alejandro. A estas actividades se suma la creatividad de escritores y la labor de la emblemática Casa de Las Américas, así como la realización

24 Entre 1994 y 2014, la ELAM formó a más de 24.000 profesionales de medicina provenientes de 83 países de América, África, Asia y Oceanía (Ruiz, 2015).

25 En palabras de su director, la película fue lanzada en una época en la que en Cuba "existía una fuerte represión a la homosexualidad [pero] para nada existe, de una manera institucional u oficial, ningún tipo de rechazo o represión a la homosexualidad" (Heredero, 2009). de giras internacionales del Ballet de Alicia Alonso.

En este contexto ocurren múltiples visitas internacionales de solidaridad y apoyo a Cuba. Solo en el año 1992 llegan 200 grupos especializados y más de 4 mil visitantes extranjeros a la isla, desde donde se recibe petróleo, papel, leche en polvo y trigo, y algunas medicinas provenientes de más de cuarenta países (Suárez, 1994: 325, 326).

\subsection{Colombia: diplomacia cultural y rechazo al estigma}

A comienzos de la Posguerra Fría los complejos contextos interno y externo miden el pulso al Estado colombiano. A nivel interno, el país sortea el recrudecimiento del conflicto armado y del "narco-terrorismo", los procesos de negociación y desarme de las guerrillas EPL, Grupo Indigenista Quintín Lame, PRT, CRS y M-19. Durante este período ocurre el asesinato de desmovilizados del M-19 y de tres candidatos presidenciales, en el marco de la apertura económica y de la nueva Constitución Política de 1991. A nivel externo, la actuación del Estado se enmarca en la guerra mundial contra las drogas, la presión de Estados Unidos para su avance y la visibilidad internacional que adquiere el país en torno a la violación de derechos humanos. El Estado colombiano intenta rechazar el estigma asociado a la violación de derechos humanos, y adoptar una postura autónoma en su política exterior, pero "los intereses estratégicos estadounidenses 
relacionados con las drogas ilícitas y la seguridad, reforzaron en los años ochenta y noventa una lógica impositiva que redujo ostensiblemente los márgenes de maniobra de Colombia" (Pardo y Tokatlian, 2010). La centralidad del narcotráfico en las relaciones bilaterales con Estados Unidos, desde finales de 1980, reforzaron la asociación dependiente con este país (Tickner, 2007).

A finales de la década de 1980, luego de más de treinta años del conflicto armado interno, Colombia capta la atención de sistemas internacionales de protección de derechos humanos. Entre 1988 y 1994, período en el que se centra esta investigación, la CIDH adopta diez resoluciones declaratorias de responsabilidad del Estado por violaciones a los derechos humanos, enviando una de ellas a la Corte Interamericana de Derechos Humanos, Corte IDH (Gallón, 2002), y realizando un informe sobre Colombia en 1993. A ello se suman dos resoluciones emitidas por el Comité del Pacto de Derechos Civiles y Políticos de la onu, y las visitas a Colombia del Grupo de Trabajo sobre desapariciones forzadas en 1988, del Relator sobre ejecuciones extrajudiciales o arbitrarias en 1989, del representante del Secretario General para los Desplazados Internos, y de los Relatores Especiales sobre Tortura y sobre Ejecuciones extrajudiciales, Sumarias o Arbitrarias en 1994 (Gallón, 2002, Tate, 2007).

La circulación del estigma asociado a la violación de derechos humanos de Colombia se da en varios frentes. Además del frente propiciado por las administraciones presidenciales de Reagan y Bush para condicionar las relaciones con países de la región, se sumaron los impulsados por el activismo internacional de colombianos, oNGs defensoras de derechos humanos y la diplomacia insurgente en los que circuló el estigma. La situación de las detenciones políticas empieza a llamar la atención internacional a partir de la carta firmada por intelectuales europeos dirigida al presidente Pastrana Borrero, y de la conferencia de prensa de la Comisión de Solidaridad con los presos políticos en la que participó Gabriel García Márquez (Tate, 2007). Aplicando el marco de los derechos humanos, el activismo internacional de movimientos sociales y ongs colombianas se acrecentó durante los años 1980. A este escenario, en los '90, se sumó el despliegue de ongs colombianas de centro-derecha que denunciaban presuntos vínculos entre ONGS de izquierda con las guerrillas colombianas. Durante esta década, las ONGS colombianas empiezan a ser más activas en la Corte IDH, y en agencias de las Naciones Unidas, en especial en la CDH (Tate,2007).

El activismo internacional de colombianos exiliados y connacionales en torno a la situación de derechos humanos en su país se despliega en España, Londres, París, Nueva York, Washington y Ginebra, buscando denunciar (Tate, 2007). Su activismo en 
Europa y Estados Unidos ${ }^{26}$ se dirige contra el Estado colombiano, enfatizando su corrupción, carácter antidemocrático y sus violaciones a los derechos humanos, lo cual se visibiliza en foros, seminarios y conferencias en sedes de universidades, partidos políticos y organizaciones sociales, lobby ante gobiernos y parlamentarios (Trejos, 2013).

ONGs internacionales en derechos humanos también se suman. Por ejemplo, en su primera visita a Colombia, en 1980, Amnistía Internacional redacta un informe con recomendaciones al gobierno, solicitando proteger derechos humanos vulnerados en el marco del Estado de Sitio (Amnistía Internacional, 1980). Con apoyo militante de oNGs colombianas, desde esta década y en los ' 90 , la ong internacional documenta casos de violaciones de derechos humanos, realiza circulares e informes que visibilizan a Colombia dentro de los casos preocupantes en América Latina y el mundo (Amnistía Internacional,1989,1991,1992,1993), emite recomendaciones al gobierno de Gaviria (1991) y un llamado al gobierno presidencial entrante de Ernesto Samper para que cumpla las promesas electorales en materia de derechos humanos (Amnistía International,

26 En Estados Unidos, en los ‘80, inmigrantes colombianos crearon el Comité de Derechos Humanos de Colombia (Washington) y la Red de Apoyo de Colombia (WI, en Madison), así como apoyaron giras de activistas colombianos (Tate, 2009).
1994). En este período, Human Rights Watch y woLA, entre otras, publican informes sobre Colombia (Tate: 2009).

A su vez, las insurgencias colombianas que buscan aliados internacionales desde la Guerra Fría, contribuyen a deslegitimar al Estado colombiano en la escena internacional, denunciando sus violaciones de derechos humanos (Trejos, 2013). Entre las insurgencias, en los '80s las FARC-EP se trazan la meta de lograr reconocimiento internacional $^{27}$; en 1983 un grupo de sus comandantes viaja a Europa y Centroaméri$\mathrm{Ca}^{28}$; en 1991, junto a otros miembros de la Coordinadora Guerrillera Simón Bolívar $^{29}$, las FARC-EP realizan una gira internacional y en 1993 crean su Comisión Internacional para incrementar sus lazos con países socialistas, partidos comunistas, sindicatos y organizaciones sociales, para difundir una imagen positiva de su organización $\mathrm{y}$, a la vez, denunciar las violaciones de derechos humanos cometidas por

27 En la séptima conferencia (1983) establece "lograr el reconocimiento internacional del carácter insurgente de las FARC-EP y el inicio de una actividad diplomática que concite apoyos para la lucha revolucionaria" (Trejos, 2013:71).

28 En palabras de Bernardo, ex comandante de las farc: "Salimos al extranjero a decir: llevamos 34 años de lucha [...] estos son nuestros planteamientos políticos para el país $[\ldots]$ muchos gobiernos comenzaron a escucharnos [...] en Europa como en Centroamérica" (citado en Trejos, 2013: 76)

29 Instancia de coordinación político-militar en la que participaron las guerrillas Unión Camilista-ELN, Comando Quintín Lame, EPL, PRT, M-19 y FARC-EP. Ver Trejos, 2013. 
agentes estatales vinculados con el paramilitarismo (Trejos: 2013).

Ante las imágenes asociadas a la violación de los derechos humanos, en el marco del despliegue del narcotráfico y actos de terrorismo, entre 1988 y 1994 el gobierno colombiano se centra en dirigir la atención internacional al complejo flagelo del narcotráfico y a la violencia perpetrada por sus carteles. Desde esta postura de manejo del estigma, el Estado acepta la importancia de los derechos humanos y simultáneamente intenta evitar ser sancionado y aislado internacionalmente. Rechazando el estigma, aboga por una comprensión amplia de la compleja realidad del país y del fenómeno del narcotráfico como motor principal de la violencia. En este proceso, Colombia se acerca a otros países etiquetados como "violadores de derechos humanos" en la CDH y el Consejo de Seguridad de las Naciones Unidas para impedir que Estados Unidos y otros Estados politicen estos espacios, y que en ellos se instrumentalicen los derechos humanos para lograr intereses políticos y económicos. Por ejemplo, el Estado colombiano apoya a Cuba en la CDH, evitando su sanción, y alude a la necesidad de desideologizar las relaciones imperantes en el sistema internacional, cuestionando indirectamente la cohesión moral de la sociedad internacional, característica de la postura del rechazo del estigma según Adler-Nissen (2014). Colombia incrementa sus relaciones diplomáticas con Cuba y otros países socialistas y africanos, lo cual, en palabras del canciller colombiano de la época: "para muchos era casi 'vergonzante', [también logramos] ingresar al Consejo de Seguridad de la ONU por aclamación, junto con México, Venezuela, Perú, Brasil, Argentina y Uruguay, [...] censuramos la sangrienta invasión norteamericana a Panamá, siendo Colombia designada presidente de la reunión de consulta de la oea convocada para ese efecto [...] En Naciones Unidas se plateó la responsabilidad compartida frente al problema de las drogas" (Londoño, 2016).

Estas actuaciones están enmarcadas en la política exterior colombiana de la segunda mitad del período final de Virgilio Barco y la mitad inicial del de César Gaviria (1988-1994), en la que se redirigen las relaciones con la región andina, se expanden los vínculos con Asia, Oceanía y África, el país ingresa a la Asociación de Estados del Caribe (AEC), y ejerce la presidencia de los NOAL. El Estado establece relaciones diplomáticas con diez naciones asiáticas, cuatro de Oceanía y veintisiete países africanos; busca un renovado papel de los Estados latinoamericanos en el sistema internacional, y habla de una posible política exterior latinoamericana (Pardo, 1987, Pardo, Tokatlian, 1988; Trejos, 2012). La política exterior de Barco buscó una orientación pragmática, enfocada en temas económicos, en redefinir las relaciones con Estados Unidos, mantener una neutralidad ideológica (Pardo, 1987; Pardo, Tokatlian, 1988; Tokatlian, 1994), y poder disentir o coincidir según sus intereses 
nacionales. Entre los desacuerdos con Estados Unidos, además de los mencionados, están la insistencia en una solución negociada y pacífica en Centroamérica, la oposición al incremento del poder de veto de Estados Unidos en el Banco Interamericano de Desarrollo, y el rechazo a la instalación de un satélite norteamericano en San Andrés (Pardo 1987, Pardo y Tokatlian, 1988, Londoño 2016). Este enfoque intentó permanecer bajo el período de Gaviria, en el que se conservó a funcionarios clave, y se buscó internacionalizar la economía colombiana (Trejos, 2012). Colombia propicia el acuerdo de paz de 1992 en El Salvador.

El Estado colombiano aspira a dejar de ser percibido como "paria" y "cómplice del narcotráfico", a ser entendido como víctima, situando el foco en la compleja realidad sorteada por la sociedad colombiana acorralada por el narcotráfico como fenómeno internacional y principal motor de la violencia. El Estado busca replantear el manejo internacional de la lucha contra este fenómeno, evidenciar la necesidad de dar lugar a la corresponsabilidad en su manejo, para así romper el ciclo de violencia derivada del fenómeno y sus aliados. Se trataba de visibilizar las circunstancias que atravesaban la sociedad colombiana, víctima de la creciente demanda de narcóticos proveniente del incremental consumo de narcóticos en Estados Unidos y Europa. En este marco, simultáneamente, el gobierno busca avanzar en la institucionalización de los derechos humanos como tema ligado a la democracia.

En el Consejo de Seguridad de las Naciones Unidas, Colombia junto con Cuba, Malasia y Yemen, unifican posiciones frente a la crisis del Golfo Pérsico, la independencia de Namibia y los territorios árabes ocupados por Israel (Trejos, 2012: 165). En escenarios multilaterales, el Estado trasmite su intención de fortalecimiento de la democracia representativa; enfatiza la relación de esta búsqueda con su compromiso con los derechos humanos, y ofrece explicaciones a nivel internacional de por qué no debería etiquetársele como "violador de derechos humanos", siendo el principal de ellos el narcotráfico.

En este contexto, Colombia despliega diversas iniciativas de diplomacia cultural (Montoya, 2017), para brindar una imagen integral del país, vinculando al sector académico a las comisiones de cooperación mixtas con diversos países, para incrementar el intercambio; se reactiva el Convenio Andrés Bello y se promocionan intercambios entre Academias Diplomáticas de la región y de productos culturales de los países del G3. ${ }^{30}$ En el marco del plan de promoción de Colombia en el exterior se celebran exposiciones artísticas en Estados Unidos, Venezuela, Inglaterra, Hungría, Argentina

30 El G3 estaba integrado por México, Venezuela y Colombia, nació en 1989 y buscó acelerar la integración económica, así como armonizar políticas macroeconómicas de los tres Estados. El tratado entra en vigor en 1995. 
(Ministerio de Relaciones Exteriores de Colombia, 1993). Para impulsar el G3 se realiza el Crucero Cultural con el que México, Colombia y Venezuela llegan a once puertos del Caribe con muestras artesanales, de danza, pintura, orquestas sinfónicas y juveniles, y se llevan a cabo eventos culturales trinacionales. ${ }^{31}$ En las comisiones mixtas con países de la región, se conforma el Consejo Binacional de Universidades para realizar intercambios académicos, programas y becas (Ministerio de Relaciones Exteriores de Colombia, 1991). A este frente se suma la reactivación del Convenio Andrés Bello (САB), para una integración educativa, científica, tecnológica y cultural, entre Chile, Perú, Venezuela, Bolivia, Cuba, Ecuador, España, Panamá y Paraguay (Ministerio de Relaciones Exteriores de Colombia,1991; Montoya, 2017).La estrecha relación con Venezuela es una característica de este período.

En el exterior se realizaron ciclos de cine colombiano y foros en torno a las artes. Tiene lugar el reconocimiento internacional de películas como "María Cano", “La Mansión de Araucaima”, "Técnicas de Duelo", "Rodrigo D no futuro" y la serie "Yuruparí". Se organizaron múltiples exposiciones internacionales con obras de artes plásticas de Fernando Botero, Luis Caballero, Santiago Cárdenas, David Manzur, Nadín Ospina, María de Paz Jaramillo, María Fernanda Cardoso y Edda Cavarico.La música también tuvo representación internacional con grupos y artistas como Totó La Momposina, Martha Senn, Helenita Olivares, Carlos Vives, el Cholo Valderrama.

\section{REFLEXIONES PARA CONTINUAR}

Este artículo abordó el status sub-explorado del estigma en la literatura de las Relaciones Internacionales, y ejemplos de iniciativas de diplomacia cultural desplegada en el marco del estigma asociado a la violación de los derechos en América Latina. Al aproximarse a las experiencias de estas iniciativas desplegadas por Chile, Cuba y Colombia a inicios de la Posguerra Fría, se trataron algunos elementos asociados a la circulación del estigma, contextos y políticas exteriores.

Luego de analizar las posturas estatales de manejo del estigma, aceptación de Chile, contra-estigmatización adoptada por Cuba y rechazo del estigma asumida por Colombia,es importante indagar cómo fueron las experiencias de los agentes de diplomacia cultural que hicieron posibles las iniciativas chilenas, y sus relaciones con el estigma en medio de las luchas por la memoria post-Pinochet. ¿Cómo fueron las experiencias de los agentes de diplomacia cultural cubanos justo después de la pérdida del apoyo de la URSS y el cruel recrudecimiento del bloqueo económico de EE.UU.? ¿Cómo fueron las experiencias de los 
agentes de diplomacia cultural colombiana bajo la cruenta dinámica del narcotráfico y la violencia? ¿Cómo percibieron el estigma asociado a la violación de los derechos humanos estos tres países? ¿Cómo vivieron el poder del arte en este escenario? ¿Por qué apostaron a este medio no violento en escenarios tan complejos? ¿Cómo todo esto permite pensar la diplomacia cultural como un posible antídoto de poder de mitigación del estigma, en los casos de Chile, Colombia y Cuba?

\section{Bibliografía}

Adler-Nissen, R. (2017). "Are we 'Nazi Germans' or 'Lazy Greeks'? Negotiating International Hierarchies in the Eurocrisis",en Zarakol, Ayse (Ed), Hierarchies in World Politics. Cambridge University Press, pp. 189-218.

Adler-Nissen, R. (2016). "The Social Self in International Relations: Identity, Power and the Rediscovery of Constructivism's Symbolic Interactionist Roots", European Review of International Studies, Vol. 3, pp: 27-39.

Adler-Nissen, R. (2014). "Stigma Management in International Relations: Transgressive Identities, Norms, and Order in International Society", International Organization, Vol. 68, no. 1, pp. 143-176.

Alexander, J. (2016). "Culture trauma, morality and solidarity", Thesis Eleven, $\mathrm{Vol}$ 132, no 1, pp. 3-16.

Amnesty International (1994). Colombia: children and minors victims of political violence. Recuperado el 23 de mayo de 2019 de https://www.amnesty.org/en/ documents/amr23/051/1994/en/

Amnesty International (1994). Newsletter April.VOL.24, NO.4. Recuperado el 17 de mayo de 2019 de https://
www.amnesty.org/download/Documents/180000/amr230011994en.pdfhttps://www.amnesty.org/download/Documents/184000/nws210041994en.pdf

Amnesty International (1994). Political violence in Colombia: myth and reality. Recuperado el 17 de mayo de 2019 de https://www.amnesty.org/download/Documents/180000/amr230011994en.pdf

Amnistía Internacional (1994). Amnistía pide al presidente que cumpla sus promesas electorales de mejorar la situación de los derechos humanos. Recuperado el 15 de mayo de 2019 de https:// www.amnesty.org/download/Documents/180000/nws111111994es.pdf

Amnistía Internacional (1994). Preocupaciones de Amnistía Internacional ante el 51 periodo de sesiones de la $\mathrm{CDH}$ de las Naciones Unidas. Recuperado el 10 de mayo de 2019 de https://www.amnesty.org/es/documents/ior41/011/1994/es/

Amnesty International (1993). Our World; Our Rights: UN World Conference on Human Rights (14-25 June 1993): Cases for Appeals 31 March 1993. Recuperado el 10 de mayo de 2019 de https:// 
www.amnesty.org/en/documents/ ior41/008/1993/en/

Amnesty International (1993). Myth and reality: Colombia campaign-16 march 1994: cases for appeals. Recuperado el 15 de mayo de 2019 de https://www.amnesty.org/en/documents/amr23/079/1993/ en/

Amnesty International (1993). The 80th international labour conference: amnesty international's concerns relevant to the committee on application of standards and the committee on action against apartheid. Recuperado el 10 de mayo de 2019 de https://www.amnesty. org/download/Documents/192000/ior420011993en.pdf

Amnistía Internacional (1993). Preocupaciones de Amnistía Internacional ante el 50 periodo de Sesiones de la CDH de las Naciones Unidas. Recuperado el 13 de Mayo de 2019 de https://www.amnesty.org/es/search/?q=\&sort=date\&contentType $=2564 \&$ country $=38287 \& p=20$

Amnesty International (1992). Colombia: human rights defenders under attack. https://www.amnesty.org/en/ documents/amr23/041/1992/en/

Amnistía Internacional (1992). Preocupaciones de Amnistía Internacional Ante El 49 Periodo De Sesiones de la Comisión de Derechos Humanos de las Naciones Unidas. Recuperado el 15 de mayo de 2019 de https:/www.amnesty. org/es/search/?q=\&sort=date\&contentType $=2564 \&$ country $=38287 \& p=20$

Amnesty International (1992). Indigenous peoples of the Americas 1992: Second Appeal Cases And Order Form For
Photographs. Recuperado el 10 de Junio de 2019 de https://www.amnesty. org/en/documents/amr01/015/1992/en/

Amnistía Internacional (1991). Preocupaciones de Amnistía Internacional ante el 48 periodo de sesiones de la Comisión de Derechos Humanos de las $\mathrm{Na}$ ciones Unidas. Recuperado el 18 de mayo de 2019 de https://www.amnesty. org/es/search/?q=\&sort=date\&contentType $=2564 \&$ country $=38287 \& p=20$

Amnesty International (1991). Trade unionists targeted for human rights violations: Index number: AMR 01/02/91 [version electronica] Recuperado el 30 de Abril de 2019 de https:/www.amnesty.org/download/Documents/196000/ amr010021991en.pdf

Amnesty International (1991). Colombia: A Further Exchange of Views with the Colombian Government. Recuperado el 15 de mayo de 2019 de https://www.amnesty.org/en/documents/amr23/069/1991/en/ Amnesty International (1980). Recommendations of an Amnesty International Mission to the Government of the Republic of Colombia (15 January-31 January 1980). Recuperado el 16 de mayo de 2019 de https:/www.amnesty.org/download/Documents/200000/ amr230041980en.pdf

Avaria, D. (2015). "La vuelta a la democracia en Chile: La contribución de los exiliados", Aletheia, Vol.5, no.10, pp.1-16. Calandra, B.y Franco, M. (2012). La Guerra Fría Cultural en América Latina: Desafíos y Límites para una nueva mirada de las Relaciones Interamericanas. Buenos $\mathrm{Ai}$ res: Editorial Biblos. 
Capote, I. (2009). “La vigencia de los principios en la política exterior y la actuación de la diplomacia revolucionaria 50 años después”. Política Internacional, no XIII, Julio-diciembre., pp.64-73. Recuperado el 19 de Marzo de 2019 de http://www. isri.cu/sites/default/files/publicaciones/ rpi/rpi13_2009.pdf

Cárcamo, A.y Riveros, M. (1998).La Imagen de Chile en el Exterior. Santiago: Universidad Nacional Andrés Bello.

Cohen, E. (S.F). Concept of Nonviolence in International Relations. Recuperado el 18 de Junio de 2019 de https:/gjis.journals.yorku.ca/index.php/ gjis/article/download/35145/31890\#: :text=Nonviolence $\% 20$ for $\% 20$ Gandhi\%20was\%20far,principle\%20of\%20 commitment $\% 20$ to\%20nonviolence.

Cooper, A. y Momani, B. (2009). "The Challenge of Re-Branding Progressive Countries in the Gulf and Middle East: Opportunities through New Networked Engagements versus Constraints of Embedded Negative Images”. Place Branding and Public Diplomacy, Vol 5, no. 2, pp. 103 - 117.

Donfried, M. (2015). The History and Evolution of Cultural diplomacy. Institute for Cultural Diplomacy. Berlin.

Engstrom, P. (2015). “El Sistema Interamericano de Derechos Humanos y las Relaciones Estados Unidos-América Latina”, Foro Internacional, Vol. 55, no. 2 , pp. 454-502.

Gallón, G. (2002). “Diplomacia y Derechos humanos en Colombia”, en Tickner, Arlene, Cardona, Diego, Ardila, Marta (Eds.),Prioridades y desafíos de la política exterior colombiana. Bogotá: FESCOL, pp. 237-282.

Galtung, J. (1990). “Cultural Violence",Journal of Peace Research, Vol 27, no. 3, pp. 291-305.

Gienow-Hecht, J. y Donfried, M. (2010). "The Model of Cultural Diplomacy: Power, Distance, and the Promise of Civil Society", en Gienow-Hecht, Jessica, Donfried, Mark (Eds), Searching for a Cultural Diplomacy. New York: Berghahn Books, pp. 13-30.

Goffman, E. (1963). Estigma: la identidad deteriorada. Buenos Aires: Amorrortu.

Heller, C. (2003). "La cuestión cubana en los foros multilaterales", Foro Internacional, Vol. 43, no. 3, pp. 675-692.

Heredero, L. (2009). Cuba, a 15 años de "Fresa y chocolate". BBC Mundo. Recuperado el 15 de Abril de 2019 de https:// www.bbc.com/mundo/cultura_sociedad/2009/07/090708_cultura_entrevista_tabio_lh

Jiménez-Martínez, C. (2013). “Chile’s quest to improve its image abroad", Place Branding and Public Diplomacy, Vol.9. no. 4., pp. 279-290.

Joseph, G. (2004). "Lo que sabemos y lo que deberíamos saber: la nueva relevancia de América Latina en los estudios sobre la Guerra Fría”, en Spenser, Daniela (ed.), Espejos de la Guerra Fría. México, América Central y el Caribe. México DF: Ciesas-Porrúa, pp. 67-92.

Lebovic, J. y Voeten, E. (2006). "The Politics of Shame: The Condemnation of Country Human Rights Practices in the UNCHR". International Studies Quarterly, Vol. 50, no. 4, pp. 861-888. 
Londoño, J. (2016). Virgilio Barco, el valiente y último radical. Revista Semana. Recuperado el 15 de Abril de 2019 de https:/www.semana.com/opinion/articulo/julio-londono-paredes-virgilio-barco-el-valiente-y-ultimo-radical/492531

Marín, A. (2018). "El giro en la gobernanza global y los derechos humanos”. De Política, no. 10, pp.11-20.

Martínez, M. (2013). "Política sin matar. Los métodos de la acción no-violenta”. Revista Vectores de Investigación, Vol. 7, no. 7., pp. 37-90.

Milet, P. (2012). "La política exterior de Chile: enfoque histórico.1990-2010”, en Artaza, Mario, Ross, César (Eds.), La política exterior de Chile, 1990-2009: del aislamiento a la integración global, Santiago: RIL Editores, pp. 317-336.

Ministerio de Educación de Cuba (2014). Resultados de la aplicación del programa Yo sí Puedo Seguir. La Habana: Cuba. Recuperado el 30 de Junio de 2019 de http://www.fidelcastro.cu/es/ internacionalismo/alfabetizacion

Ministerio de Relaciones Exteriores de Chile (1992).Proyecto Imagen Corporativa para Chile. Santiago: Biblioteca Histórica de ProChile.

Ministerio de Relaciones Exteriores de la República de Colombia (1993). Memoria al Congreso 1992-1993. Bogotá: Imprenta y publicaciones Fuerzas Militares.

Ministerio de Relaciones Exteriores de la República de Colombia. (1991). Memoria al Congreso Nacional 1990-1991. Bogotá: Imprenta Nacional de Colombia. Ministerio de Relaciones Exteriores de la República de Cuba MINREX (2018).
Informe de Cuba sobre la resolución 72/4 de la Asamblea General de las Naciones Unidas. "Necesidad de poner fin al bloqueo económico, comercial y financiero impuesto por los Estados Unidos de América Contra Cuba. La Habana. Recuperado el 20 de Junio de 2019 de http://www.acnu.org.cu/sites/default/ files/informe_bloqueo_2018.pdf

Montes, R. (2018). La detención de Augusto Pinochet: 20 años del caso que transformó la justicia internacional. El país. Recuperado el 16 de octubre de 2019 de https://elpais. com/internacional/2018/10/16/america/1539652824_848459.html

Montoya, S. (2017). Política Exterior y Diplomacia cultural: hacia Colombia en Posconflicto. Bogotá: Universidad Católica de Colombia.

Navarro, A. (2019). Diplomacia Cultural y Democracia en Chile. Recuperado el 12 de noviembre de 2019 de https://arturo-navarro.blogspot.com/2019/10/diplomacia-cultural-y-democracia-en.html

Nye, J. (2004). Soft power: the means to success in world politics. New York: Public Affairs.

Pardo, R. (1987). “La política exterior de la administración Barco”, Análisis Político, no 2, pp. 64-73.

Pardo, R. y Tokatlian, J.G. (2010). “Segundo centenario y política exterior: una reflexión en torno a Colombia”, en, Calderon, María, Restrepo, Isabel (eds), Colombia 1910-2010. Bogotá: Taurus, pp. 199-274.

Pardo, R. y Tokatlian, J.G. (1988). “Teoría y práctica de las relaciones 
internacionales: El caso de Colombia”, Estudios Internacionales, Vol 21, no. 81, pp. 94-135.

Passport Index (2017). Recuperado el 19 de junio de 2019 de https://www.passportindex.org/byRank.php

Portes, A. (2003). "La máquina política cubano-estadounidense: reflexiones sobre su origen y permanencia”. Foro Internacional, no. 173, pp. 608-626.

Prieto, M.C. (2011). Branding the Chilean nation: Sociocultural change, national identity and international image. (Tesis doctoral). Leiden University.

Romero, A. (2017). "La política exterior cubana y la actualización del modelo económico en un entorno cambiante". Pensamiento Propio, no 45, pp. 81-110.

Rossbach, D.; Hayes, J.; Wilson, I.; Kleinheider, J.; Myers, M.; Genna, G.; Westfall, A. \& Haakenson, T. (2013). "Forum: German Studies and the Euro Crisis”, German Studies Review, Vol. 36, no. 1, pp.125-45.

Ruiz, J. (2015). “La cooperación Sur-Sur como elemento de acción exterior: la experiencia cubana”. Revista Española de Ciencia Política, no. 39, pp.139-164.

Schoultz, L. (2014). Human Rights and United States Policy Toward Latin America. Princeton: Princeton University Press.

Schulz, C-A. y Levic, L. (2019). "Regional Patterns of Multilateral Treaty Cooperation: Is there a Latin American "Commitment Gap"?”. Ponencia presentada en la 60 Convención Anual de Isa, Marzo 27 -30, Toronto, Canadá.

Sinha, P. (2013). "China's Cultural Diplomacy: Historical Origin, Modern
Methods and Strategic Outcomes". China Reasearch Center, Vol. 12, No. 2. Recuperado el 25 de Junio de 2019 de https:/www.chinacenter.net/2014/china_currents/12-2/chinas-cultural-diplomacy-historical-origin-modern-methods-and-strategic-outcomes/

Son, K-Y. (2007). "Entrenching 'identity norms' of tolerance and engagement: Lessons from rapprochement between north and South Korea, Review of International Studies, Vol 33, no. 3, 489-509.

Stern, S. (2010). Reckoning with Pinochet the memory question in democratic Chile, 1989-2006. Durham: Duke University Press.

Suárez, L. (1994). “Cuba: La Política Exterior en El Periodo Especial”. Estudios Internacionales, Vol. 27, no. 107-108), pp. 307-334.

Tate, W. (2007). Counting the dead: The culture and politics of human rights activism in Colombia. Berkeley: University of California Press.

Tate, W. (2009). "El activismo estadounidense en derechos humanos y el Plan Colombia”. Colombia Internacional, no. 69, pp. 50-69.

Tickner, A. (2007). "Intervención por invitación. Claves de la política exterior colombiana y de sus debilidades principales”. Colombia Internacional, no. 65, pp. 90-111.

Tokatlian, J. (1994). "La política exterior del Gobierno del presidente Virgilio Barco: En busca de la autonomía perdida”, en Deas, Malcolm, Ossa, Carlos (coord.). El gobierno Barco: política, economía y desarrollo social, 1986-1990, 
Bogotá: FEDESARROLLO/Fondo Cultural Cafetero.

Tolley, H. (1984). “The Concealed Crack in the Citadel: The United Nations Commission on Human Rights' Response to Confidential Communications”. Human Rights Quarterly, Vol 6, no. 4, pp. 420-462.

Torres, M. (1999).In the Land of Mirrors: $\mathrm{Cu}$ ban Exile Politics in the United States, Ann Arbor: University of Michigan Press.

Trejos, L. (2013). “Actividad política de un actor no estatal colombiano en Centroamérica y el Caribe. El caso de las Fuerzas Armadas Revolucionarias de Colombia -Ejército del Pueblo (FARCEP)". Memorias, no. 19, pp. 69- 91

Trejos, L. (2013). “Las FARC-EP en Europa y Centroamérica. Una mirada desde la categoría de actor no estatal". OPE$R A$, no.13, pp. 109-121.

Trejos, L. (2012). "La política exterior del Estado colombiano (1958-2002). Muchas continuidades con pocas rupturas". Justicia, no. 22, pp. 154-173.

Van Klaveren, A. (2012). "La promoción de la democracia como principio de la política exterior de Chile”, en Artaza, Mario, Ross, César (eds.), La política exterior de Chile, 1990-2009: del aislamiento a la integración global. Santiago; RIL Editores, pp. 115-139.
Van Klaveren, A. (2011). “La política exterior de Chile durante los gobiernos de la Concertación (1990-2010)". Estudios Internacionales, Vol.44, no.169, pp.155-172. Villanueva, C. (2011). "The rise and fall of Mexico's international image: stereotypical identities, media strategies and diplomacy dilemmas". Place Branding and Public Diplomacy, Vol 7, no. 1, pp. 23-31.

Wastnidge, E. (2015). "The Modalities of Iranian Soft Power: From Cultural Diplomacy to Soft War". POLITICS, Vol.3. No. 3-4, pp. 364-377.

Wilhelmy, M.y Durán, R. (2003). “Los principales rasgos de la política exterior chilena entre 1973 y el 2000". Revista de Ciencia Política, Vol. XXIII, no 2, pp. 273-286. Wood, S. (2017). "Rebranding the nation: Germany's image politics”. International Politics, Vol 54, no. 2, pp.161-181.

Zarakol, A. (2014). "What Made the Modern World Hang Together: Socialization or Stigmatization?”. International Theory, Vol 6, no. 2, pp. 311-332.

Zourek, M. (2017). “Los viajes de los intelectuales latinoamericanos a Europa oriental 1947-1956: Organización, circuitos de contacto y reflexiones”. Ars \& Humanitas, Vol 11, no 2, pp. 331-347. 